\title{
Comprehensive aerial survey quantifies high methane emissions from the New Mexico Permian Basin
}

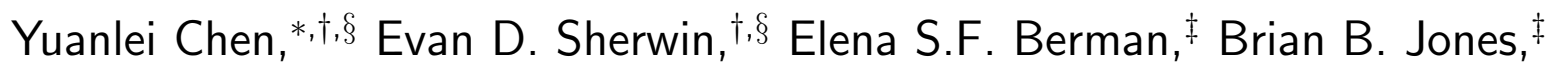 \\ Matthew P. Gordon ${ }^{\ddagger}$ Erin B. Wetherley, ${ }^{\ddagger}$ Eric A. Kort, ${ }^{\top}$ and Adam R. Brandt ${ }^{\dagger}$ \\ $\dagger$ Energy Resources Engineering, Stanford University, Stanford, CA 94305, USA \\ $\ddagger$ Kairos Aerospace, Mountain View, CA 94040, USA \\ 【Climate and Space Sciences and Engineering, University of Michigan, Ann Arbor, MI \\ 48109, USA \\ $\S$ Denotes equal contribution \\ E-mail: yuliac@stanford.edu
}

Abstract

Limiting emissions of climate-warming methane from oil and gas $(\mathrm{O} \& \mathrm{G})$ is a major opportunity for short-term climate benefits. We deploy a basin-wide airborne survey of the New Mexico Permian Basin, spanning 35,923 km², 26,292 active wells, and over 15,000 km of natural gas pipelines using an independently-validated hyperspectral methane point source detection and quantification system. The airborne survey repeatedly visited over $90 \%$ of the active wells in the survey region throughout October 2018 to January 2020, totaling 117,658 well visits. We estimate total O\&G methane emissions in this area at $194(+72 /-68,95 \% \mathrm{CI})$ metric tonnes per hour $(\mathrm{t} / \mathrm{h})$, or $9.4 \%(+3.5 \% /-3.3 \%)$ of gross gas production. $50 \%$ of observed emissions come from 
large emission sources with persistence-averaged emission rates over $308 \mathrm{~kg} / \mathrm{h}$. This result emphasizes the importance of capturing low-probability, high-consequence events through basin-wide surveys when estimating regional O\&G methane emissions.

\section{Keywords}

Methane emissions, oil and gas, leakage, hyperspectral imaging, remote sensing, airborne survey

\section{Synopsis}

Surveying nearly every oil and gas asset in a region substantially increases estimates of total emissions of climate-warming methane.

\section{Introduction}

Methane, the primary constituent of natural gas (NG), is a potent greenhouse gas (GHG) with a global warming potential at least 30 times larger than carbon dioxide. ${ }^{1}$ While the transition to renewable energy is accelerating, inertia in industrial systems and the need for stable energy supply means that NG will continue to be used for decades. Therefore, reducing the GHG intensity of oil and gas $(\mathrm{O} \& \mathrm{G})$ through preventing methane emissions is an important mitigation opportunity.

The Permian Basin in Texas and New Mexico produces more oil than all but five countries in the world. ${ }^{2}$ Over the past decade, Permian oil production has quadrupled and gas production has tripled. ${ }^{2}$ However, as production from this oil-rich basin has increased, incentives to limit the resulting emissions of climate-warming methane have been lacking. Economically, operators view oil as the primary product, ${ }^{3}$ because natural gas prices in the region have remained low - or sometimes even negative - due in part to a lack of gas takeaway capacity. ${ }^{4}$ 
Non-peer reviewed preprint submitted to EarthArXiv.

Regulations have also been slow to catch up to the pace of development - New Mexico in particular has never before had large-scale oil production, and is only now implementing state-level regulations on venting and flaring. ${ }^{5}$ Taken together, the lack of economic and regulatory incentives to reduce methane emissions has likely contributed to high methane emissions in the Permian Basin. ${ }^{6-8}$

A number of studies have found abnormally high methane emissions from O\&G operations in the Permian Basin. With aircraft- and tower- based methane concentration measurements, Lyon et al. estimated the NG production loss at 3.3\% in a subdomain of the Permian. ${ }^{7}$ Zhang et al. and Schneising et al. apply inversion methods based on satellite measurements, finding a NG production loss rate of roughly $3.7 \%$ for the full Texas and New Mexico Permian. ${ }^{69}$ More recently, a hyperspectral airborne survey by Cusworth et al. characterizes the very heavy tail of site-level methane emissions in the Permian Basin, finding 2,874 methane plumes above $100 \mathrm{~kg} / \mathrm{h}$ and 457 above $1,000 \mathrm{~kg} / \mathrm{h}$, larger than any observation previously found in ground-based methane surveys. ${ }^{10}$ Because of the different methods and coverage areas of these studies, direct comparison of their results is challenging and uncertainty remains about the emissions rates in the Permian Basin.

However, these studies consistently find emissions significantly in excess of government estimates. The US Environmental Protection Agency (EPA) Greenhouse Gas Inventory (GHGI) estimates a national NG production loss rate of 1.5\%. ${ }^{11,12}$ But the GHGI has been identified as a conservative estimate of methane emissions, ${ }^{11,13,14}$ and a recent alternative estimate finds a US national average NG production loss rate of $2.3 \%$ based on a synthesis of measurements from across the O\&G supply chain. ${ }^{11}$ Note that the Permian findings are even higher than this adjusted national average. One possible driver of even larger emissions in the Permian might be the large leaks found by Cusworth et al.: infrequent large leaks (so-called "super-emitters") are thought to play an important role in driving total emissions. Across many studies, the top $5 \%$ of leaks contribute over $50 \%$ of emissions. ${ }^{15}$

How are these figures still so uncertain? In short: field measurements are noisy and 
the high expense of surveys means that most studies to date have been very data-limited. For example: the largest multi-paper synthesis dataset of ground-based site-level methane measurements includes measurements from $\sim 1000$ well sites across 5 different studies. ${ }^{13}$ Given that there are over one million active O\&G wells in the US, this is a relatively small sample size. Especially given the importance of infrequent super-emitters in driving total emissions, such sample sizes are difficult to extrapolate.

We bridge this gap using a novel approach: A basin-wide aerial survey capable of measuring emissions from nearly every asset in an $O \& G$ producing region with an instrument capable of quantifying and attributing medium-to-large point-source emissions. This work allows us to identify emissions larger than any documented in ground-based surveys, and to obtain sample sizes orders of magnitude larger than prior approaches.

\section{Materials and Methods}

\section{Repeated comprehensive airborne survey}

We use a basin-wide dataset from aerial surveys performed by Kairos Aerospace (henceforth "Kairos") to evaluate medium-to-large point-source emissions in the New Mexico Permian Basin. Kairos' technology consists of an integrated infrared imaging spectrometer, optical camera, global positioning system (GPS), and inertial motion unit. ${ }^{16}$ The instrument is flown on an airborne platform at $\sim 900 \mathrm{~m}$ above ground, and generates methane plume images superimposed over concurrent optical images (see example in Figure 1a).

Sherwin, Chen et al. evaluated the Kairos technology by conducting an independent, single-blind test of the system including 234 total measurements. They found 1) no false positives; 2) a minimum detection level of $5 \mathrm{~kg}$ of methane per hour per meter per second of wind ( $\mathrm{kgh} / \mathrm{mps})$ and a partial detection range of $5-15 \mathrm{kgh} / \mathrm{mps}$; and 3) an $R^{2}$ value of 0.84 between the measured and actual release volumes across a wide range of release sizes tested (18-1025 kg/h) above the technology's detection limit. This study showed the technology's 

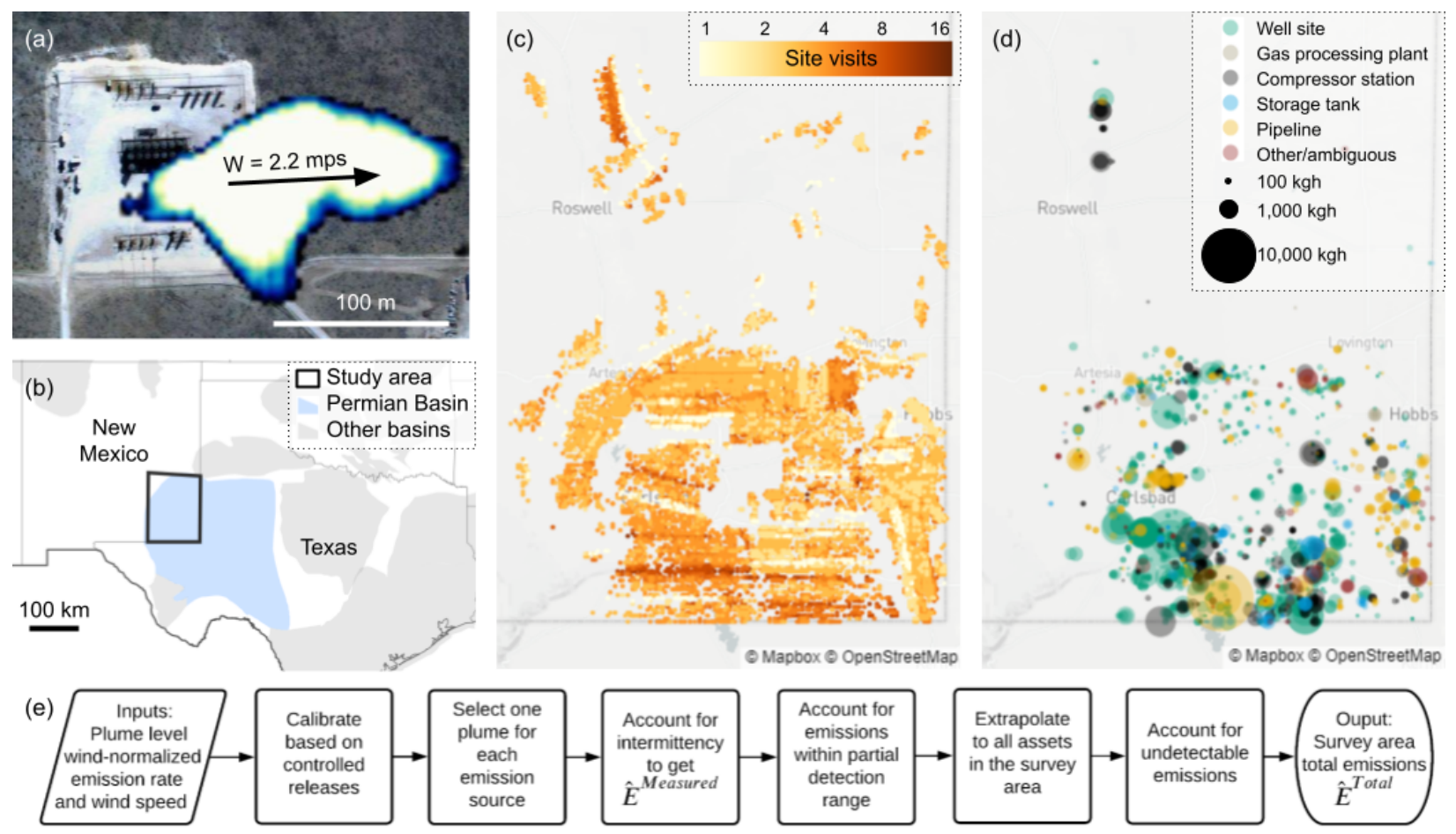

Figure 1: Methane emission data and analysis workflow. (a) Methane plume from an O\&G site. White pixels indicate a high probability of excess methane. (b) Permian Basin map with the survey area outlined in black. Other sedimentary basins are colored grey. ${ }^{17}$ (c) Number of measurements of each point asset (pipelines not included). The colorbar is on a logarithmic scale. (d) 1,985 detected methane plumes colored by asset type and scaled by plume size. (e) Analysis workflow for estimating survey area total emissions based on methane plume observations.

ability to quantify super-emitters in the field. ${ }^{18}$ See the Supplementary Information (SI), Section S1 for detailed controlled release results.

The Kairos survey of the New Mexico Permian was conducted over 115 flight days from October 2018 to January 2020 (Figure 1b). The campaign surveyed 35,923 km² (13,870 sq. mi.) and 26,292 active wells, or 91.2\% of all active wells in the covered region. All data were anonymized using procedures described in the SI, Section S2.2.

Each surveyed non-pipeline facility was observed an average of 4 times. Accounting for these repeated measurements, a total of 117,658 visits to wells were performed. Figure 1c shows the number of measurements of each point asset (non-pipeline). Multiple overflights also allowed for more frequent sampling in the temporal dimension and provided insights into 
Non-peer reviewed preprint submitted to EarthArXiv.

emission intermittency. The SI, Section S2 details the flight plans and Section S3 presents an analysis of intermittency.

\section{Basin-wide emissions quantification}

A methane survey will detect some number of plumes, each of which is associated to an emission source. An emission source is defined as a point coordinate with one or more methane plumes observed during the campaign. The SI, Section S4.2 describes the association process.

Figure 1e illustrates the analysis workflow to derive survey-area total emissions. The SI, Section S5.1 describes each step in detail. For each plume, Kairos reports a wind-independent emission rate in $\mathrm{kgh} / \mathrm{mps}$, and we multiply this rate with the National Oceanographic and Atmospheric Administration's High Resolution Rapid Refresh (HRRR) wind speed reanalysis estimate at the imaging time and plume coordinates to calculate emission rate in $\mathrm{kg} / \mathrm{h}$ for each plume using the method described in Duren et al. ${ }^{19}$

We then refer to the the single-blind test of the instrument by Sherwin, Chen et al. to determine the instrument's detection limit and quantification accuracy and precision (see the SI, Section S1). Data from the single-blind test shows the instrument's apparent overestimation tendency for larger releases, possibly due to an underlying nonlinearity or a boundary bias for calibration (see the SI, Section S1.6). Using a sublinear correlation from the singleblind test, we calibrate the plume-level emission rates in $\mathrm{kg} / \mathrm{h}$. The single-blind test also quantified the measurement uncertainties, which is modeled as a fixed percent error distribution at all emission levels, indicating that the modeled absolute error scales linearly with emission magnitude (see the SI, Section S1.5). To account for the measurement error in the New Mexico Permian Basin study, we assume that the percent error follows a normal distribution and apply this error to the plume-level emission rates with 1000 Monte Carlo realizations.

For each realization of the Monte Carlo approach, we then select one plume for each emission source if multiple plumes were observed during repeated overflights. Then we 
Non-peer reviewed preprint submitted to EarthArXiv.

multiply the selected plume quantification with a binary term to account for intermittency. The binary term is modeled to follow a Bernoulli distribution with p equal to fraction of overflights that observed emissions at each emission source. Basin-wide directly-measured emission $\left(\hat{E}^{\text {Measured }}\right)$ is the sum of all emission source level emissions after accounting for intermittency. The SI, Section S3 explains why this is an unbiased estimate of total measured emissions.

To account for undetected emissions in the partial detection range of Kairos' technology, we add to $\hat{E}^{\text {Measured }}$ the expected amount of emissions undetected within the partial detection range based on both the detection probabilities and what was observed in the partial detection range during the New Mexico Permian campaign (see the SI, Section S1 and S5.1). We then scale up the estimate to the full study area, the black polygon in Figure 1, assuming that emissions in uncovered areas scale with the number of O\&G wells in the area.

Below Kairos' minimum detection threshold, we assume that emissions are described by a combination of the fractional loss rate from Alvarez et al. of $2.2 \%$ for production and midstream as well as the emission size distribution from Omara et al. ${ }^{11,13}$ Assuming winds from the New Mexico Permian, Kairos would be able to detect $63 \%$ of emissions from Omara et al. 2018, translating to a fractional loss rate of $0.8 \%$ for emissions below the detection threshold in this study. See the SI, Section S1.4 and S5.1 for partial detection definition and detailed steps to account for undetected emissions. We denote the total emissions after incorporating undetected emissions as $\hat{E}^{\text {Total }}$.

\section{Results and Discussion}

\section{Large basin-wide methane emissions quantified}

The campaign detected 1985 methane plume observations from 958 distinct emission sources, indicating that for the average emissions source, approximately two different overflights observed a plume. Using the approach described in Materials and methods, our estimate 
for measured emissions $\left(\hat{E}^{\text {Measured }}\right)$ from the New Mexico Permian is $153(+71 /-70,95 \%$ CI) metric tonnes per hour $(\mathrm{t} / \mathrm{h})$, shown as the left bar in Figure 2a. This corresponds to $7.4 \% \pm 3.4 \%$ of gross gas production in the full survey area.
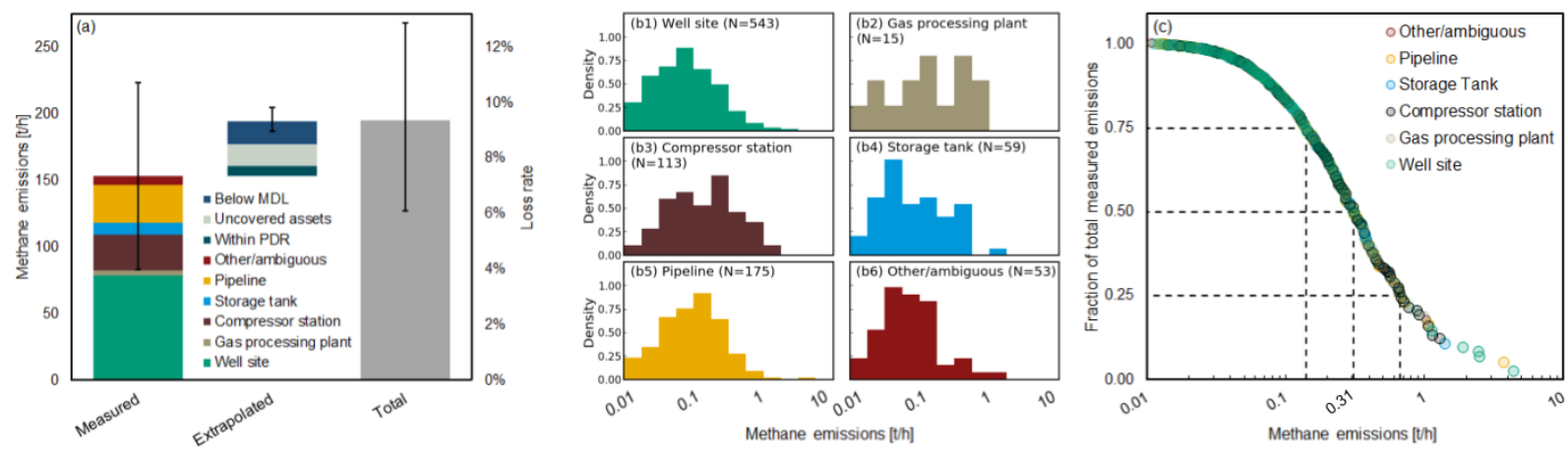

Figure 2: Persistence-averaged emissions. (a) The left bar shows directly measured methane emissions $\left(\hat{E}^{\text {Measured }}\right)$ broken down by asset type. The error bars indicate $95 \%$ confidence intervals. The middle bar breaks down extrapolated emissions into undetected emissions within the partial detection range (PDR), emissions from assets not measured in the survey area, and emissions that are below minimum detection limit (MDL). The right bar shows that the estimate of total methane emissions in the survey area from upstream and midstream O\&G operations is $194(+72 /-68) \mathrm{t} / \mathrm{h}, 9.4 \%(+3.5 \% /-3.3 \%)$ of gross gas production. (b) The distribution of asset-type-specific persistence-averaged emission source sizes, which follow heavy-tailed distributions. (c) Cumulative emission fraction as a function of persistenceaveraged emission source sizes.

Accounting for partial detection, emissions below minimum detection limit, and scaling up to assets not covered in this aerial campaign, the total survey area emission estimate $\left(\hat{E}^{\text {Total }}\right)$ is $194(+72 /-68) \mathrm{t} / \mathrm{h}$, equivalent to $9.4 \%(+3.5 \% /-3.3 \%)$ of gross gas production.

A breakdown of $\hat{E}^{\text {Measured }}$ by emission source asset type reveals that $79 \pm 46$ of the $153 \mathrm{t} / \mathrm{h}$ of measured emissions comes from well sites. A "well site" is defined here as the ensemble of all assets (including wells, gathering lines, storage tanks, and compressor stations) found on a congruent gravel or concrete area containing at least one well. Midstream assets were also a significant source, with $29 \pm 20 \mathrm{t} / \mathrm{h}$ emitted from pipelines (including underground gas gathering pipelines) and $26 \pm 16 \mathrm{t} / \mathrm{h}$ emitted from compressor stations without a well on site. The remainder was emitted from stand-alone storage tank sites $(9 \pm 6 \mathrm{t} / \mathrm{h})$, gas processing plants $(4 \pm 2 \mathrm{t} / \mathrm{h})$, and other or ambiguous sources $(7 \pm 4 \mathrm{t} / \mathrm{h})$. See the SI, Section S4.2 for 
Non-peer reviewed preprint submitted to EarthArXiv.

definitions of each asset type and the asset attribution method.

Figure $2 \mathrm{~b}$ shows the distribution of persistence-averaged emission source sizes and indicates heavy-tailed distributions of emission sizes across asset types. As displayed in Figure 2c, $50 \%$ of total emissions are from $118(\sim 12 \%)$ of the 958 sources, those larger than $308 \mathrm{~kg} / \mathrm{h}$. The heavy tail gets even heavier for the largest emissions and contains a disproportionate number of midstream assets. The largest persistence-averaged emission source emits at 4.3 $\mathrm{t} / \mathrm{h}$. The persistence of the heavy tail for distributions of large emissions demonstrates the significant potential for mitigating methane by detecting and fixing these high-consequence sources.

Sensitivity tests show robust support for a mean natural gas fractional loss rate of at least $8.1 \%$ of gas produced. As listed in Table 1, switching from a sublinear fit to a linear fit for the calibration step, described in the SI, Section S7, brings the loss rate estimate up to $10.2 \%(+4.1 \% /-3.6 \%)$. A linear fit forced through the origin leads to an estimate of $11.0 \%(+5.0 \% /-4.6 \%)$. In the calibration fitting process, leaving out large controlled releases improves the statistical validity of the fit due to the underlying asymmetric error distribution at high emission rates, and also increases the total emission estimate, as described in the SI, Section S1.5. Using an alternative wind dataset (the commercial Dark Sky wind reanalysis product) results in comparable emissions estimates both for low- and high-time-resolution versions of the data. ${ }^{20}$

To provide a conservative estimate for the loss rate, we apply three additional sensitivity scenarios: 1) disallow extrapolation and assume that emission rates cannot exceed the largest controlled release rate $(1025 \mathrm{~kg} / \mathrm{h}) ; 2)$ exclude the top 20 largest plumes ( $1 \%$ of the dataset); and 3) assume that there are no emissions from plumes below the Kairos minimum detection limit. These conservative approaches still result in mean loss rate estimates over $8 \%$ with a $5^{\text {th }}$ percentile estimate never falling below $5.2 \%$.

These sensitivity cases show that even the lower-bound estimates of the conservative scenarios based on our basin-wide data are larger than estimates from other Permian studies: 
Non-peer reviewed preprint submitted to EarthArXiv.

Table 1: Survey-area total methane emission rate and loss rate estimates. Presented as a fraction of total methane production, for the base case and seven sensitivity cases.

\begin{tabular}{c|rrr|rrr}
\hline Cases & \multicolumn{3}{|c|}{$\hat{E}^{\text {Total }}(\mathrm{t} / \mathrm{h})$} & \multicolumn{3}{|c}{$\%$ NG production loss } \\
& Mean & $5^{\text {th }} \%$ & $95^{\text {th }} \%$ & Mean & $5^{\text {th } \%}$ & $95^{\text {th } \%}$ \\
\hline Base case & 194 & 126 & 266 & $9.4 \%$ & $6.1 \%$ & $12.9 \%$ \\
Linear fit for calibration & 212 & 136 & 296 & $10.2 \%$ & $6.6 \%$ & $14.3 \%$ \\
Linear fit forced through origin for calibration & 228 & 131 & 335 & $11.0 \%$ & $6.4 \%$ & $16.0 \%$ \\
Cutoff at 1 $\sigma$ below max controlled release & 216 & 137 & 301 & $10.4 \%$ & $6.9 \%$ & $14.6 \%$ \\
Dark Sky wind high time resolution & 181 & 124 & 244 & $8.7 \%$ & $6.1 \%$ & $11.8 \%$ \\
Dark Sky wind low time resolution & 217 & 142 & 301 & $10.4 \%$ & $6.8 \%$ & $14.3 \%$ \\
Disable extrapolation & 167 & 119 & 220 & $8.1 \%$ & $5.7 \%$ & $10.6 \%$ \\
Exclude top 20 plumes & 173 & 117 & 233 & $8.3 \%$ & $5.5 \%$ & $11.2 \%$ \\
No below minimum detection emissions & 177 & 109 & 249 & $8.5 \%$ & $5.2 \%$ & $12.0 \%$ \\
\hline
\end{tabular}

$3.7 \%$ by the Zhang et al. and Schneising et al. satellite-based top-down studies and 3.3\% by the Lyon et al. tower- and airplane-based top-down study, although these studies include both Texas and New Mexico. ${ }^{6,7,9}$ Applying our basin-wide quantification method to data from Cusworth et al. in the overlapping region of New Mexico, we find a fractional loss rate of $4.4 \%$ for directly-measured emissions. ${ }^{10}$ This rises to $5.9 \%$ after accounting for an evidently higher effective minimum detection threshold compared to the Kairos survey (see the SI, Section S9).

\section{Importance of large sample size and direct measurement}

Figure 3 compares our results with Zhang et al., which uses a methane flux inversion approach based on satellite data to calculate a NG production loss rate of $3.7 \% \pm 0.7 \%$, or $331 \mathrm{t} / \mathrm{h}$ in a region of the Permian spanning both New Mexico and Texas. We apply spatial, time-of-day, and study period alignment corrections (described in the SI, Section S8) to enable a more direct comparison to our study results. These adjustments increase the estimate of Zhang et al. from $64 \mathrm{t} / \mathrm{h}$ (in our study area) to $106 \mathrm{t} / \mathrm{h}$. This is still below $\hat{E}^{\text {Measured }}$.

The remaining discrepancy may be due to various causes. First, their study focused on a larger spatial domain and was not focused on NM Permian. Some modeling assumptions in 

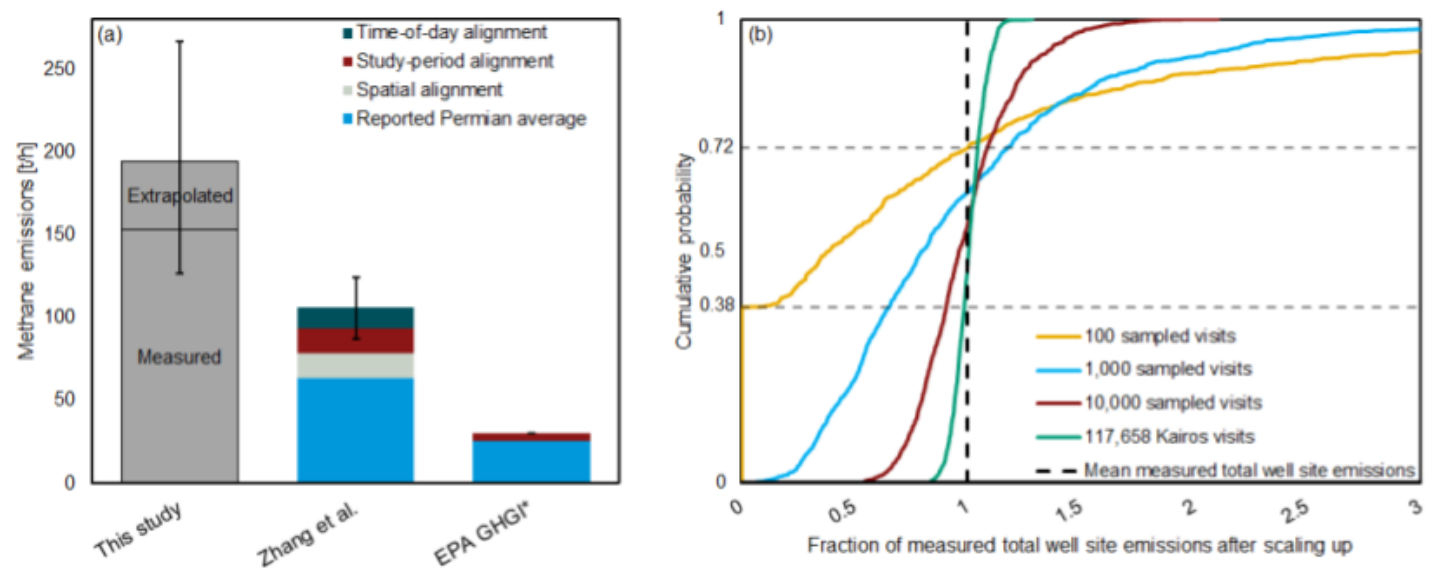

Figure 3: Comparison with other studies and the importance of large sample size for sampling from a heavy-tailed distribution. (a) Estimated methane emissions from the New Mexico Permian from this study (left bar), Zhang et al. posterior (middle bar), and EPA GHGI (right bar). Beige, grey, and red bars indicate adjustments performed by this study to better allow for direct comparison of results (see the SI, Section S8). *Note that the EPA GHGI presented here is based on the gridded GHGI in, ${ }^{6}$ which takes into account the production growth between the last official EPA GHGI publication in 2012 and the Zhang et al. study period. (b) Simulations showing the probability of under- or over-estimating total emissions if only a subset of the 117,658 well visits in this study were conducted. Surveying 100 wells generates a $72 \%$ chance of underestimating survey-area total emissions, while visiting 1000, 10,000, and 117,658 wells generates a $63 \%, 56 \%$, and $50 \%$ chance of underestimation, respectively. The computed ratios of simulated emissions detection over mean Kairos-measured well site emissions are plotted on the x-axis.

Zhang et al. may also introduce conservatism (a conservative prior flux estimate and sptial concentration of prior emissions at O\&G production sites, as opposed to midstream assets). We explore this comparison more in the SI, Section S8.

It is important to explore further a key strength of our method compared to prior studies: very large study sample size. We explore this by simulating the impact of small sample sizes on total emissions estimates (Figure 3b).

Suppose that we only visited 100 wells, a typical sample size for ground-based campaigns. Based on a random subsample of 100 well visits from our full dataset of 117,658 effective well visits, and using the same minimum detection limit as Kairos, this hypothetical 100well survey would detect no emissions $38 \%$ of the time and would find average emissions 
Non-peer reviewed preprint submitted to EarthArXiv.

lower than the basin-wide survey $72 \%$ of the time (based on 1000 Monte Carlo realizations). Median emissions would be $38 \%$ our full survey estimate. In a small number of Monte Carlo realizations (8\%), scaling up the 100 sampled visits results in overestimates by a factor of two or more. Over many Monte Carlo realizations, a sample size of 100 will ultimately converge on the larger survey results, but this does not reflect the reality of field campaigns: there are usually no more than a few such campaigns for a given basin in a given decade and averaging over 1000 hypothetical surveys does not apply.

Figure 3b shows that increasing the sample size per fictional survey to 1000 well visits generates an underestimate of total emissions $63 \%$ of the time, while a size of 10,000 effectively captures large-scale behavior. The extremely non-normal distribution of leak sizes plays a large role here and intuition developed with normally distributed phenomena may be deceiving. In normally distributed phenomena, small sample sizes cause variance but not bias, and increasing sample size reduces the variance in the estimated emissions. But with our observed contribution of super-emitters, the median estimate of a fictional survey shifts strongly to the right as our sample size increases: at 100 well visits the median estimate is $38 \%$ of our estimate, at 1000 visits this increases to $79 \%$, and at 10,000 visits it increases to $96 \%$ of our estimate.

\section{Airplane-detectable emitters drive total emissions}

While aerial detection technologies have been critiqued for their relatively high minimum detection limit, our results suggest an alternative interpretation: the error introduced from the small sample sizes feasible with ground campaigns may overwhelm any benefits they get from a lower detection threshold. For example, below-minimum-detection-limit emissions account for $9 \%(+4 \% /-3 \%)$ of our study total, suggesting that higher sensitivity would lead to only a modest increase in total estimated emissions relative to simulated levels.

In conclusion, we conducted a site-level, basin-wide field survey of methane emissions in one of the most active oil-producing regions in the world. We estimate emissions to be 
$9.4 \%(+3.5 \% /-3.3 \%)$ of the gross gas production for the region, much higher than found in previous studies with overlapping, although not identical, domains. The increase is partly because our method allows us to inspect the entire O\&G-producing population using an independently-verified instrument capable of detecting large methane emissions. This allows us to identify the largest emissions from all assets surveyed, sidestepping the statistical uncertainties of scaling-up small samples of ground-based field measurements.

Previous studies rarely observed emissions larger than $10 \mathrm{~kg} / \mathrm{h}$ at a single site, yet our basin-wide survey of over 30,000 assets uncovered 1958 methane plumes above this size. ${ }^{8,13}$ This includes many emissions over 100 and $1000 \mathrm{~kg} / \mathrm{h}$, with emissions above $308 \mathrm{~kg} / \mathrm{h}$ accounting for half of measured emissions for the region. While it is possible that the New Mexico Permian was an anomaly during this study period, the clear impact of large emissions found by this study suggests that estimates from ground-based methane surveys may be underestimating total emissions by missing low-frequency, high-impact large emissions.

\section{Acknowledgments}

The authors would like to thank the Kairos Aerospace team for collecting and preparing the data for this study. The authors gratefully acknowledge the help from Ritesh Gautam, Ben Hmiel, David Lyon, and Mark Omara at the Environmental Defense Fund, Yuzhong Zhang currently at Westlake University, Anna Robertson and Shane Murphy at the University of Wyoming, and Daniel Cusworth and Riley Duren at Carbon Mapper, and Andrew Thorpe at NASA's Jet Propulsion Lab for assisting in comparing this aerial survey with their methane studies. The authors would like to thank Jeffrey Rutherford at Stanford University for providing comments on the study.

\section{Author Information}

Yuanlei Chen and Evan D. Sherwin contributed equally to this work. 
Non-peer reviewed preprint submitted to EarthArXiv.

\section{Funding Sources}

This study was funded by the Stanford Natural Gas Initiative, an industry consortium that supports independent research at Stanford University. Analysis was supported in part by the Alfred P. Sloan Foundation Grant G-2019-12451 in support of the Flaring and Fossil Fuels: Uncovering Emissions and Losses (F3UEL) project.

\section{Data availability}

The data required to reproduce key results in this article are available at https://github. com/KairosAerospace/stanford_nm_data_2021. While the remaining data from this study are not available for open release due to confidentiality concerns, Kairos Aerospace is committed to working with research groups studying methane emissions. Access may be granted, but must be done directly through Kairos Aerospace. Interested researchers should contact research-collaborations@kairosaerospace.com.

\section{References}

(1) U.S. Environmental Protection Agency (EPA), Understanding Global Warming Potentials. https://www.epa.gov/ghgemissions/ understanding-global-warming-potentials.

(2) U.S. Energy Information Administration (EIA), Permian region drilling productivity report. https://www. eia.gov/petroleum/drilling/pdf/permian.pdf, 2020.

(3) U.S. Energy Information Administration (EIA), Natural gas spot and futures prices (NYMEX). https://www.eia.gov/dnav/ng/ng_pri_fut_s1_d.htm. 
Non-peer reviewed preprint submitted to EarthArXiv.

(4) U.S. Energy Information Administration (EIA), Permian Basin natural gas prices up as a new pipeline nears completion. https://www.eia.gov/naturalgas/weekly/ archivenew_ngwu/2020/03_19/\#tabs-rigs-1, 2019.

(5) U.S. Department of Energy (DOE), New Mexico natural gas flaring and venting regulations. https://www. energy.gov/sites/prod/files/2019/08/f66/New\%20Mexico. pdf, 2019.

(6) Zhang, Y.; Gautam, R.; Pandey, S.; Omara, M.; Maasakkers, J. D.; Sadavarte, P.; Lyon, D.; Nesser, H.; Sulprizio, M. P.; Varon, D. J., et al. Quantifying methane emissions from the largest oil-producing basin in the United States from space. Science advances 2020, 6, eaaz5120.

(7) Lyon, D. R.; Hmiel, B.; Gautam, R.; Omara, M.; Roberts, K. A.; Barkley, Z. R.; Davis, K. J.; Miles, N. L.; Monteiro, V. C.; Richardson, S. J., et al. Concurrent variation in oil and gas methane emissions and oil price during the COVID-19 pandemic. Atmospheric Chemistry and Physics 2021, 21, 6605-6626.

(8) Robertson, A. M.; Edie, R.; Field, R. A.; Lyon, D.; McVay, R.; Omara, M.; ZavalaAraiza, D.; Murphy, S. M. New Mexico Permian Basin Measured Well Pad Methane Emissions Are a Factor of 5-9 Times Higher Than US EPA Estimates. Environmental Science \& Technology 2020,

(9) Schneising, O.; Buchwitz, M.; Reuter, M.; Vanselow, S.; Bovensmann, H.; Burrows, J. P. Remote sensing of methane leakage from natural gas and petroleum systems revisited. Atmospheric Chemistry and Physics 2020, 20, 9169-9182.

(10) Cusworth, D. H.; Duren, R. M.; Thorpe, A. K.; Olson-Duvall, W.; Heckler, J.; Chapman, J. W.; Eastwood, M. L.; Helmlinger, M. C.; Green, R. O.; Asner, G. P., et al. Intermittency of Large Methane Emitters in the Permian Basin. Environmental Science E Technology Letters 2021, 
(11) Alvarez, R. A.; Zavala-Araiza, D.; Lyon, D. R.; Allen, D. T.; Barkley, Z. R.; Brandt, A. R.; Davis, K. J.; Herndon, S. C.; Jacob, D. J.; Karion, A., et al. Assessment of methane emissions from the US oil and gas supply chain. Science 2018, 361, 186-188.

(12) Maasakkers, J. D.; Jacob, D. J.; Sulprizio, M. P.; Turner, A. J.; Weitz, M.; Wirth, T.; Hight, C.; DeFigueiredo, M.; Desai, M.; Schmeltz, R., et al. Gridded national inventory of US methane emissions. Environmental science \& technology 2016, 50, 13123-13133.

(13) Omara, M.; Zimmerman, N.; Sullivan, M. R.; Li, X.; Ellis, A.; Cesa, R.; Subramanian, R.; Presto, A. A.; Robinson, A. L. Methane emissions from natural gas production sites in the United States: Data synthesis and national estimate. Environmental science \& technology 2018, 52, 12915-12925.

(14) Rutherford, J. S.; Sherwin, E. D.; Ravikumar, A. P.; Heath, G. A.; Englander, J.; Cooley, D.; Lyon, D.; Omara, M.; Langfitt, Q.; Brandt, A. R. Closing the gap: Explaining persistent underestimation by US oil and natural gas production-segment methane inventories [Preprint]. https://doi.org/10.31223/X5JC7T, 2020.

(15) Brandt, A. R.; Heath, G.; Kort, E.; O’Sullivan, F.; Pétron, G.; Jordaan, S. M.; Tans, P.; Wilcox, J.; Gopstein, A.; Arent, D., et al. Methane leaks from North American natural gas systems. Science 2014, 343, 733-735.

(16) Kairos Aerospace, Technical White Paper: Methane Detection. 2019.

(17) U.S. Energy Information Administration (EIA), Maps: Oil and Gas Exploration, Resources, and Production. https://www.eia.gov/maps/maps.htm.

(18) Sherwin, E. D.; Chen, Y.; Ravikumar, A. P.; Brandt, A. R. Single-blind test of airplanebased hyperspectral methane detection via controlled releases. Elementa: Science of the Anthropocene 2021, 9 . 
(19) Duren, R. M. et al. California's methane super-emitters. Nature 2019, 575, 180-184.

(20) Dark Sky by Apple Inc., Dark Sky data attribution. https://darksky.net/ attribution.

(21) Jones, B. B.; Dieker, S. W. Systems and methods for detecting gas leaks. 2019; http://patft. uspto.gov/netacgi/nph-Parser?Sect1=PT02\&Sect2=HITOFF\&p=1\&

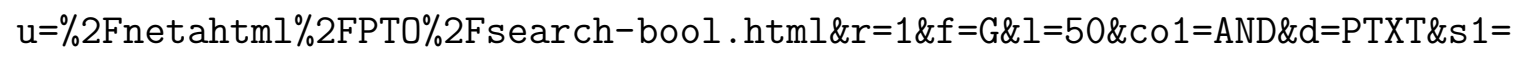
$10267729 \& 0 S=10267729 \& R S=10267729$.

(22) Kairos Aerospace, Methane Emissions Quantification. https://kairosaerospace. com/wp-content/uploads/2020/12/ Kairos-Emissions-Quantification-20201218.pdf, 2020.

(23) Ravikumar, A. P.; Sreedhara, S.; Wang, J.; Englander, J.; Roda-Stuart, D.; Bell, C.; Zimmerle, D.; Lyon, D.; Mogstad, I.; Ratner, B., et al. Single-blind inter-comparison of methane detection technologies-results from the Stanford/EDF Mobile Monitoring Challenge. Elementa: Science of the Anthropocene 2019, 7.

(24) Bañuelos-Ruedas, F.; Camacho, C. Á.; Rios-Marcuello, S. Methodologies used in the extrapolation of wind speed data at different heights and its impact in the wind energy resource assessment in a region. Wind farm-technical regulations, potential estimation and siting assessment 2011, 97-114.

(25) Grossman, A. Dark Sky Has a New Home. https://blog.darksky.net/ dark-sky-has-a-new-home/\#: : text=By $\backslash \% 20$ Adam $\backslash \% 20$ Grossman $\backslash \% 20$ on $\backslash$ $\% 20$ August, be $\backslash \% 20$ receiving $\ \% 20 a \backslash \% 20$ full $\backslash \% 20$ refund., 2020.

(26) HRRR archive at the University of Utah. http://home.chpc.utah.edu/ u0553130/ Brian_Blaylock/. 
(27) Ravikumar, A. P.; Wang, J.; McGuire, M.; Bell, C. S.; Zimmerle, D.; Brandt, A. R. "Good versus good enough?" Empirical tests of methane leak detection sensitivity of a commercial infrared camera. Environmental science $\&$ technology 2018, 52, 2368-2374.

(28) Eastern Research Group, City of Fort Worth natural gas air quality study. https://www.fortworthtexas.gov/departments/development-services/ gaswells/air-quality-study/final, 2011.

(29) Environmental Defense Fund, Permian Methane Analysis Project (PermianMAP). https : //www .permianmap.org/.

(30) Royal Netherlands Meteorological Institute, TROPOMI methane data product. http: //www.tropomi.eu/data-products/methane.

(31) GHGSat, GHGSat global emissions monitoring services. https://www.ghgsat.com/ data-products-analytics/.

(32) European Space Agency, About GOSAT-2. https://earth.esa.int/eogateway/ missions/gosat-2?text=methane.

(33) Enverus, Exploration and Production. https://www.enverus.com/industry/ exploration-and-production/.

(34) National Oceanic and Atmospheric Administration (NOAA), High Resolution Rapid Refresh (HRRR) CONUS 2-D Fields GRIB2 table documentation. https:// rapidrefresh.noaa.gov/hrrr/HRRRv4_GRIB2_WRFTWO.txt, 2020.

(35) Environmental Defense Fund, New Data: Permian Oil \& Gas Producers Releasing Methane at Three Times National Rate. https://www.edf.org/media/ new-data-permian-oil-gas-producers-releasing-methane-three-times-national-rate.

(36) Rohatgi, A. Webplotdigitizer: Version 4.4. 2020; https://automeris.io/ WebPlotDigitizer. 
Non-peer reviewed preprint submitted to EarthArXiv.

\section{${ }_{330}$ Disclosures}

381 Elena S.F. Berman, Brian B. Jones, Matthew P. Gordon, and Erin B. Wetherley are em382 ployees of Kairos Aerospace. The remaining authors have no competing interests to declare. 